\title{
Research on the development status and trend of chassis control technology by wire
}

\author{
Chang Yang*, and Rongliang Liang \\ China Automotive Technology and Research Center Co.,Ltd., China
}

\begin{abstract}
Keywords: automotive engineering, vehicle by wire, chassis integrated control, application prospect.
\end{abstract}

\begin{abstract}
With the rapid development of automobile electronic industry, more and more electronic control technologies are replacing the traditional mechanical devices of automobile. Modern automobile chassis control technology is developing towards the direction of wire control. The wire control system will replace the traditional control system which mainly consists of hydraulic, pneumatic and mechanical systems, so as to realize the integration with other systems. In this paper, the development status of vehicle by wire control technology in various countries, as well as the composition, working principle and control method of vehicle by wire steering system and brake by wire system are summarized, the key technologies affecting the development of vehicle by wire control are summarized, and the application of by wire control technology in the future automotive field is prospected.
\end{abstract}

\section{Foreword}

Safety, Comfort, Energy Saving and Environmental protection are the direction and eternal theme of automobile development.Electronic, Intelligent, Electric and Rebiologically capable are the effective measures and means to realize the above development direction. The adoption of wire control technology can provide a strong technical guarantee for the realization of automobile electronization, intelligentization, electrification and rebiologicalization. With the continuous development of automotive electronic technology, the application of vehicle wire control technology in the field of automotive chassis can replace the traditional mechanical and hydraulic systems with accurate electronic sensors and electronic actuators, and the traditional automotive operating actuators will inevitably have a fundamental revolution.

Automobile control technology developed from fly-by-wire.The technology uses sensors to turn the driver's action into an electrical signal and send it to the processor, which sends instructions to the corresponding actuator to complete the driver's operation intention. The wire control car adopts the same control mode, sensing the driver's driving intention through the sensor, and passing the electrical signal to the controller, the controller controls the actuator to work, realizing the steering, braking, driving and other

\footnotetext{
${ }^{*}$ Corresponding author: yangchang@catarc.ac.cn
} 
functions of the car, so as to replace the control mode of the traditional car by mechanical, hydraulic, pneumatic transmission control signal.

Vehicle Drive-by-wire technology application make the vehicle chassis arrangement more reasonable optimization, make the vehicle from the working condition of input, process, processing, and actuation perform more accurate and efficient, is the realization of the vehicle under complex conditions further enhance the necessary means of handling and driving comfort, but also the future automatic driving vehicle, intelligent transportation, the carrier of green travel implementation.

\section{Development status of wire control automobile}

In the 1950 s and 1960 s, many $R \& D$ companies transformed the original mechanical connection into the control signal between steering wheel and steering wheel, and realized the early prototype of steering system by wire.

In recent years, with the increasing maturity of automotive electronic technology and communication fusion technology, wire control technology can be widely used in the automotive industry. In 1990, German Benz started the in-depth research on the front-wheel Drive-by-wire steering system, and installed the drive-by-wire steering system developed by it on the concept vehicle F400Carving. The car in the steering, braking, suspension and body control aspects of the use of wire control technology. Chrysler has developed an electric-driven concept car, the R129, which eliminates the steering wheel, accelerator pedals and brake pedals and USES full joystick control, enabling drive-by-wire technology. In 2003 and 2005, American general motors also launched hy-wire and Sequel, which use hydrogen fuel as energy and realize the starting, steering and braking of cars through motor drive, as shown in Figure 1. Japan's Nissan also launched the PIVO and EA2 cars in 2006 and 2008, while France's Citroen, South Korea's Hyundai and kia have also launched cars using the technology.

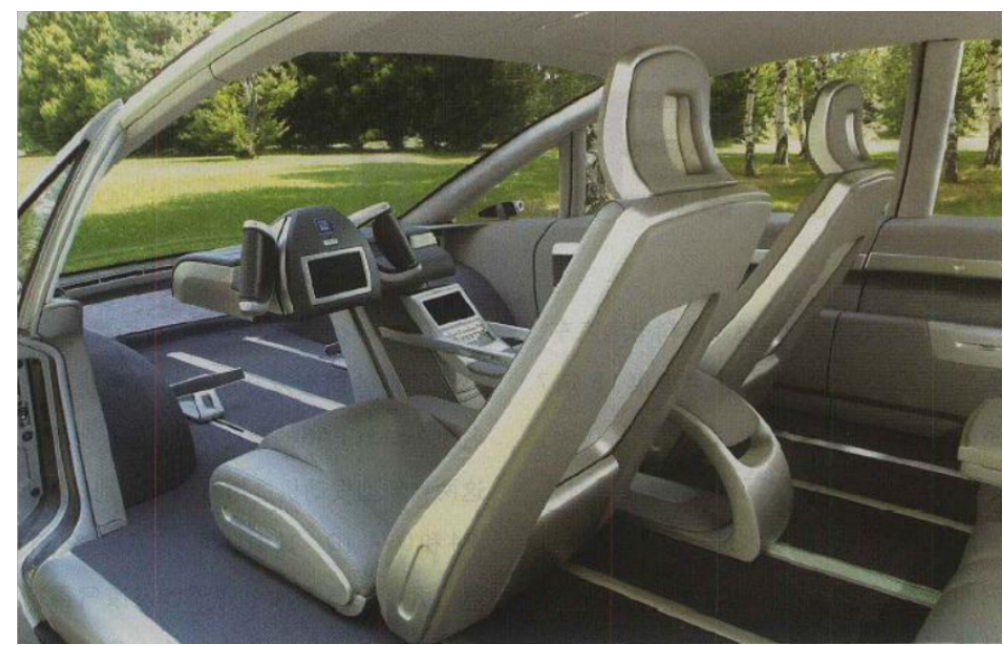

Fig. 1. General motors car by wire.

Chinese enterprises are relatively late in the research of wire control technology compared with foreign countries, but as the electrification and intelligent development of the auto industry is accelerating, China has the opportunity to win the lead in the development and application of electric vehicles and intelligent driving technology globally. As the core control technology of the vehicle, the development of wire control technology 
is related to the application of autonomous driving, new energy, fuel cell and other technical fields. Therefore, its importance and necessity are gradually becoming the focus of attention and competition of automobile enterprises and suppliers.

In 2019, global chassis system integrator schaeffler and hunan xiangjiang new area management committee formally signed an investment agreement in changsha. Technologies and products such as Space Drive technology, 90 intelligent drive-by steering system and Mover platform were introduced into China, and they were verified on Schaeffler Mover, which was launched in Shanghai auto show in the same year, as shown in figure 2. The four wheels are powered by the schaeffler's intelligent steering Drive module, which is controlled by Space Drive technology using an electromechanical "drive-by-wire" steering system that enables the vehicle to steer at a 90 Angle.

In addition to schaeffler, domestic main engine factory and Bosch, mainland, ZF are online control technology layout. At present, saic, baic, gac and other main engine plants have developed mature wirecontrol vehicles. Bosch's iBooster was launched in early 2013 and applied to Volkswagen, saic and other relevant models. The n-booster line control system produced by Shanghai nassen has been applied to Beijing automotive new energy EC series in batches. The line control system MK C1 developed and produced by continental group can achieve efficient braking energy recovery and will be mass-produced in China by the end of this year.

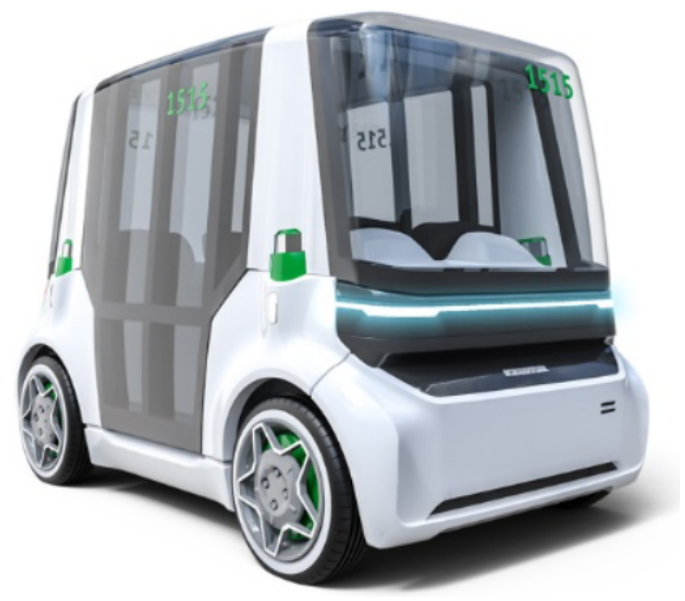

Fig. 2. Schaeffler mover.

\section{Application of automotive chassis wire control technology}

\subsection{Steering by wire}

Compared with the traditional vehicle steering technology, the most essential difference is that the wire steering eliminates the mechanical connection between the steering wheel and the wheel, the steering wheel Angle data is obtained by the sensor, which is converted into the specific driving force data, and the motor is used to push the steering wheel to turn the wheel to complete the vehicle steering. The line-controlled steering system is mainly composed of steering wheel assembly, controller and steering execution assembly. Its structure is shown in the figure: 


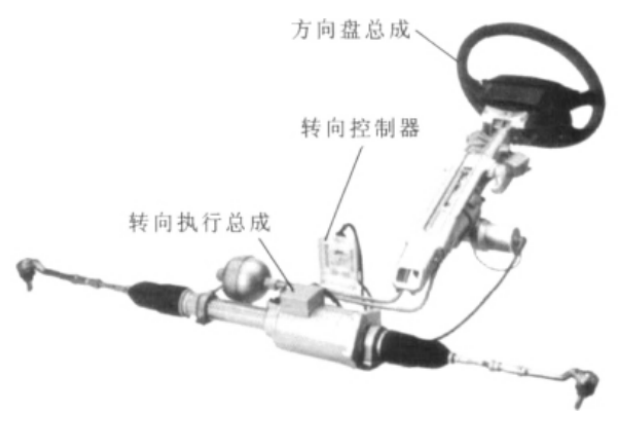

Fig. 3. Steering by wire system.

Wire control steering system works will be the driver's steering wheel assembly intent (by measuring the steering wheel Angle) is converted into digital signals, passed to the controller, the controller of the acquisition of signal analysis processing, discriminant vehicle motion state, control motor drive wheel steering to perform, realize the driver's steering intention. In addition, the controller can filter the unnecessary vibration according to the driving intention, vehicle condition and road condition, and send torque signal to the steering wheel assembly in real time to generate steering wheel torque to provide the driver with the corresponding road sense information.

\subsubsection{Line steering system layout}

Since the wire steering system has no mechanical connection and relies entirely on electronic components, fault tolerance measures are needed. The realization of fault-tolerant technology mainly relies on redundancy, that is, the design has certain redundancy in function or quantity. When a part of the wire control system fails or fails, the redundancy part can guarantee the normal work of the system.

Since the wire steering system has no mechanical connection and relies entirely on electronic components, fault tolerance measures are needed. The realization of fault-tolerant technology mainly relies on redundancy, that is, the design has certain redundancy in function or quantity. When a part of the wire control system fails or fails, the redundancy part can guarantee the normal work of the system.

Table 1. Comparison of layout of line steering system.

\begin{tabular}{|c|c|c|c|}
\hline Arrangement & Product & Advantage & Disadvantage \\
\hline $\begin{array}{c}\text { Front } \\
\text { Wheel Steering }\end{array}$ & ZF 2001 & $\begin{array}{l}\text { The structure is simple } \\
\text { and easy to arrange }\end{array}$ & $\begin{array}{l}\text { High motor power, poor } \\
\text { redundancy }\end{array}$ \\
\hline Double motor & $\begin{array}{l}\text { Infiniti } \\
\text { Q50 }\end{array}$ & $\begin{array}{l}\text { It has good redundancy } \\
\text { and requires little power } \\
\text { for a single motor }\end{array}$ & $\begin{array}{l}\text { Redundant algorithm } \\
\text { increases, cost increases }\end{array}$ \\
\hline $\begin{array}{l}\text { Dual motor } \\
\text { independence }\end{array}$ & $\begin{array}{l}\text { Stanford } \\
\text { universityX }\end{array}$ & $\begin{array}{l}\text { Remove steering gear } \\
\text { components to improve }\end{array}$ & $\begin{array}{l}\text { There is no redundancy } \\
\text { and the cooperative }\end{array}$ \\
\hline The front wheel steering & 1 & the degree of freedom & $\begin{array}{l}\text { control algorithm is } \\
\text { complex }\end{array}$ \\
\hline $\begin{array}{l}\text { Rear wheel active } \\
\text { steering }\end{array}$ & $\mathrm{ZF} \mathrm{AKC}$ & $\begin{array}{l}\text { Increased freedom, } \\
\text { enhanced steering ability }\end{array}$ & $\begin{array}{l}\text { The structure is complex } \\
\text { and the control algorithm } \\
\text { is complex }\end{array}$ \\
\hline $\begin{array}{l}\text { Four-wheel independent } \\
\text { steering }\end{array}$ & UFEV & $\begin{array}{l}\text { The control freedom is the } \\
\text { largest, the steering ability } \\
\text { is the strongest }\end{array}$ & $\begin{array}{l}\text { The system has complex } \\
\text { structure and low } \\
\text { reliability }\end{array}$ \\
\hline
\end{tabular}




\subsubsection{Wire steering control}

The car steering is controlled by wire control technology, the most important feature of which is that the steering Angle transmission ratio can be freely designed from the steering wheel to the steering wheel. The active steering control strategy of linear steering system is generally divided into two types: the active steering control strategy to improve vehicle maneuverability and the active steering control strategy to improve vehicle stability.

In terms of improving vehicle maneuverability, the design principle of active steering control strategy is to reduce the steering transmission ratio and improve steering sensitivity at low speed. At high speed, the steering transmission ratio is increased to ensure the steering stability and obtain better driving conditions. There are three main research methods: (1) in the speed of information, on the basis of the introduction of the steering wheel Angle, yawing velocity and lateral acceleration of vehicle state information such as nonlinear fitting, get to variable transmission ratio function equation (2) considering the people - car - road closed-loop system complexity and strong nonlinear, there is a big difficult to establish accurate mathematical model, the introduction of fuzzy control and neural network intelligent control methods, such as design variable transmission ratio will speed, steering wheel Angle and yawing angular velocity variables as input, output for steering gear ratio. The method does not require an accurate mathematical model of the system and has good robustness. (3) from the Angle that yaw gain or lateral acceleration gain is constant, the active steering control strategy of the linear steering system is designed to improve the vehicle's maneuverability and comfort.

In terms of improving the vehicle stability, the active steering control strategy of the line-controlled steering system mainly controls the vehicle's front wheel Angle to change the side force of tires and generate compensating yaw moment to ensure the stability of the vehicle. Due to the limitation of tire force saturation, the stability control ability of drive-by-wire steering system is weaker than that of active braking stability system. However, the stability control of the line steering system has little influence on the speed, so it has certain advantages in driving comfort. The stability control of the linear steering system mainly adopts the vehicle state feedback control method. The feedback variables include yaw velocity, lateral deflection Angle of the center of mass, lateral acceleration and lateral inclination Angle.

\subsubsection{Advantages of line steering system}

Compared with the traditional steering mechanism, the advantages of wire steering system are as follows:

1 Improve the degree of free design, easy to control the system layout. Due to the lack of mechanical connection of the wire steering, it is easy to change the left cabin driver into the right cabin driver. At the same time, the car crash safety is improved to some extent due to the elimination of steering column and steering gear.

2 It is beneficial to the integration of chassis control technology. At present more and more chassis electronic control system into the use of cars. For example, DYC and ESP control the longitudinal forces of the wheels to compensate for the loss of driving direction and body instability caused by the change of lateral acceleration or yaw angular velocity, so as to increase the vehicle's control stability. The adoption of wire steering system is conducive to the integration of chassis control technology, the comprehensive use of active suspension, ASR, DYC, ESP and other electronic control system sensors, data sharing, comprehensive consideration of the vehicle turning and lateral stability control, further improve the vehicle handling stability and safety. 
3 The use of wire steering system is conducive to reduce the cost of chassis development. In the future, the development trend of wire control steering is to use the wire control system of the joystick, because of the elimination of steering column, pulley and other components, to facilitate the overall layout of the chassis design. The drive-by-wire steering system can be applied to other models by modifying some parameters of the control strategy, which saves a lot of time for the design and development of new models and helps the automobile manufacturers to seize the market opportunities in the highly competitive automobile industry.

\subsection{Braking by wire}

Wire control system, that is, the use of wire to replace part or all the brake line, through the controller control electronic components to control the braking force. There are currently two types of wire-control systems, electrohydraulic wire-control systems (EHB) and electro-mechanical braking (EMB). Among them, EHB is developed on the basis of the traditional hydraulic brake, but compared with the traditional hydraulic brake, EHB has a significant improvement. It has compact structure, improved braking efficiency, convenient and reliable control, significantly reduced braking noise, no need for vacuum device, and provides better pedal feeling.

The biggest difference between the EMB and EHB is that it no longer requires brake fluid and hydraulic components. The braking torque is generated entirely by the motor-driven actuators mounted on the four tires. Therefore, the brake master cylinder, hydraulic pipeline and so on are correspondingly cancelled, greatly simplifying the structure of the braking system, and more significantly, with the elimination of brake fluid, pollution is reduced. However, the EMB has not yet been used in mass production due to cost, reliability and relevant policies and regulations. As an extension of the traditional hydraulic braking system, EHB is positively related to the accumulation of ABS, ESP and other product technologies. The combination of the above functions can be easily realized through the control algorithm, and the improvement of vehicle braking stability has been favored by the main engine manufacturers. Figure 4 shows the main components of the EHB line control system.

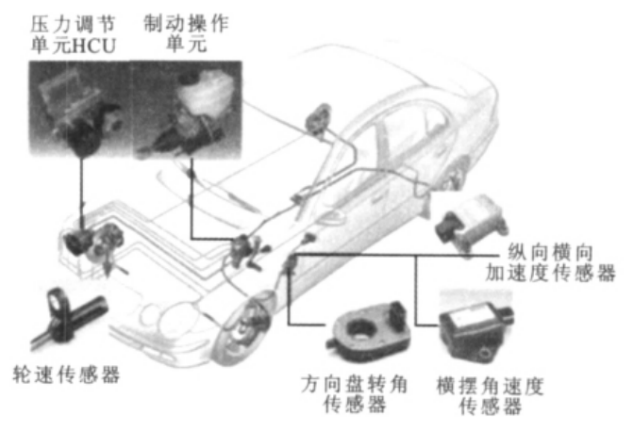

Fig. 4. Braking by wire system.

\subsubsection{Braking by wire stability control}

Since the linear control system is a closed-loop control, the controller receives the signal from the brake pedal and the signal from the wheel sensor in real time to identify whether the wheel is locked or skidding, so as to control the braking force of the wheel, and further optimize the anti-lock braking function and stability control performance. 
At present, the research on EHB system at home and abroad has been focused on product development. In the literature [21], the structure and working principle of the wire controlled hydraulic braking system are studied, and the corresponding mathematical model is established. The adjustment of the vehicle motion state is realized through the stability control of yaw moment distribution between wheels and the decision of wheel cylinder pressure, so as to improve the longitudinal and lateral stability of the vehicle. In the literature [22], a hydraulic system model of the braking circuit during normal operation of EHB is established, and a stability control strategy based on single control variable yaw velocity is proposed. The control simulation results under typical working conditions show that the control algorithm can effectively control the stability of the vehicle under the conditions of high speed and low adhesion road surface.

\subsubsection{Advantages of braking by wire}

With the improvement of motor performance, the reduction of the cost of electronic components and the support of relevant regulations and policies, EMB has become the consensus of the automobile industry to replace EHB in the future. Compared with traditional hydraulic braking system, electromechanical braking system has its advantages:

1. The system does not need brake fluid, easy and simple maintenance, wire connection, good durability of the system. Because there is no hydraulic pipeline and brake fluid, so there is no hydraulic oil pollution problem, improve the environmental protection of the car.

2. Mechanical and electrical connection, rapid signal transmission and sensitive response. The chassis braking performance can be optimized by modifying the software in the ECU and configuring the relevant parameters.

3. It is simple and fast to manufacture, assemble and test the line control system. The modular structure of the brake assembly reduces the mechanical braking components, which is conducive to the arrangement of the car and improves the passive safety.

\section{Key technology of wire control chassis}

The application of wire control chassis is inseparable from the development of automotive electronics technology and integrated control theory of vehicle dynamics. Due to cancelled the traditional drive-by-wire technology of pneumatic, hydraulic and mechanical connection, instead of sensor, ECU, electromagnetic actuator, thus the precision of the sensor and resolution, the performance of the motor controller, system fault diagnosis and fault-tolerant control and auto bus communication and arbitration ability of all relations between the drive-by-wire chassis control technology application.

\subsection{Sensor technology}

Automotive sensors have matured with the development of the automotive industry. The application of sensor technology has greatly promoted the development of automobile intelligence, while the wire control chassis control technology has higher requirements on sensors. The vehicle chassis sensor continuously feedback the vehicle status information to the controller in time, and the controller controls the actuator according to the established control strategy. Therefore, the precision and resolution of the sensor directly affect the precision and performance of the control system. It is one of the key technologies to develop the sensor with low cost, good reliability, high precision and small volume. 
In addition, there are many kinds of sensors in automobile chassis, so how to integrate many sensors with different functions with smaller and smaller size and higher precision has become a new research direction. It is an effective way to achieve this goal by developing multi-functional sensors, integrated sensors and intelligent sensors that integrate the peripheral circuits such as shaping, amplification and compensation, and integrating sensors, processing circuits and computer chips on the same chip with large-scale integrated circuits. Data fusion technology can also effectively reduce the number of sensors and improve the measurement accuracy.

\subsection{Motor and controller technology}

The wire control system realizes the target control of actuator mainly through the controller driving various motors. The performance of motor and its controller greatly affects the overall performance of wire control vehicle. The motor of the wire control system mainly takes the position, the speed or the torque as the control target, the power varies from ten watts to several kilowatts. For low power motor, stepper motor or dc motor can be used, such as throttle control motor, oil pump motor, etc. In the aspect of high-power motor, permanent magnet synchronous motor has been more and more widely used, such as wire steering motor, electric wheel drive motor and so on. Electric vehicles with full range control need to consume more electric energy due to the simultaneous operation of multiple motors, which requires to improve the motor power density, controller power density, system efficiency and maximum efficiency as far as possible, and expand the range of efficiency zone. This can not only reduce the load of the motor, controller and system power supply, improve the design redundancy, but also has important significance for the wire control system to save energy and enhance the system dynamic performance. In addition, the reliability, safety and electromagnetic compatibility of the motor and controller are also important prerequisites for the safety of vehicle integrated control.

\subsection{Fault-tolerant control techniques}

Automotive wire control chassis control system has the traditional mechanical or hydraulic systems do not have the technical advantages. At the same time, because it is a new and sophisticated advanced electronic system, it is not yet as reliable as mechanical or hydraulic components, and it has a different failure mode from traditional vehicles.

In order to improve the reliability and security of the automobile, drive-by-wire chassis system fault tolerant control must be taken, when some parts malfunction or failure, their function in the system whether can use the system completely or partly replace other parts, the system can continue to maintain the rule of performance or loss of the most basic function, further to achieve optimum performance of fault systems, it has gradually become a line control system in the practical application of key problems to be resolved.

\subsection{Automobile bus technology}

The overall application of wire control technology in automobile chassis not only marks the overall transformation of automobile chassis from mechanization to electronization, but also puts forward higher requirements for automobile bus technology. As some wirecontrol chassis components require redundancy in function to ensure that the components can still work normally when certain faults occur, wirecontrol chassis control technology not only requires fast bus transmission speed and good real-time response, but also requires low communication time dispersion and high reliability. At present, there are mainly two kinds of wire control technology bus protocols: one is TTP/C, each node of the protocol has two 
repeated channel connections; The other is FlexRay, a bus protocol that supports both time-triggered and event-triggered access, as shown in Table 2:

Table 2. Ain bus protocols for wire control technology.

\begin{tabular}{lcl}
\hline Name & Protocol characteristics & User \\
\hline \multirow{2}{*}{ TTP/C } & Strict safety design & Volkswagen \\
& Multiple repeat channel connections & Delphi \\
& High node cost & Audi \\
FlexRay & Redundant backup good & BMW \\
& Two channel data transfer & Bosch \\
& Fast transmission speed & GM \\
\hline
\end{tabular}

\section{Development trend of wire control technology}

The emergence of wire control technology has changed the traditional concept of automotive electronic technology. In the traditional automobile, the automobile electronic system has been used as the auxiliary system of the mechanical system to ensure the accuracy of the operation and the comfort of the vehicle. Although the proportion of automotive electronics in cars is increasing as control technology is used more and more widely in automobiles, it is still only an auxiliary system. At the same time, whether it is braking anti-lock system or steering stability system, it is always only a part of the vehicle operating conditions control. The emergence of wire control technology will greatly change this situation. It makes the electronic system become the core system of all the automobile systems, and all the vehicle control signals are no longer transmitted through the mechanical system, but through the electronic system control transmission. At the same time, it does not control the vehicle under a single working condition such as braking and steering, but the whole vehicle under complex working conditions. Therefore, as early as the world engineers automotive forum in 2004, people on the development of automotive wire chassis on the future of the car will be "four wheels and a computer" design idea.

With the development of wire control technology, high-speed vehicle-mounted network and the improvement of sensor and processor performance, the organic combination of integrated vehicle control, wire control and multi-sensor information fusion system will become an important direction of the research and development of wire control vehicles.

\section{Conclusion}

(1) the development status of wire control technology in the global automotive industry is introduced. As a green carrier of intelligent network vehicles, intelligent transportation and Shared travel, wire control vehicles have become the focus of the future layout of the automotive industry.

(2) the working principles and control methods of line-controlled chassis midline control and line-controlled steering are summarized, and the key technologies affecting the development of line-controlled chassis are expounded and analyzed.

(3) the drive-by-wire chassis have enforced and the advantages of high accuracy, high in the future intelligent transportation field, combined with multiple conditions scenario fusion technology, is truly guarantee the premise of vehicle automated driving, but its functional redundancy design, performance testing and reliability validation is still the key generic technology in mass for its application.

\section{Reference}


1. 宗长富, 麦 莉, 郭学立. 汽车前轮电子转向系统 $[\mathrm{J}]$. 中国机械工程, 2004

2. 宗长富, 刘 凯. 汽车线控驱动技术的发展 $[\mathrm{J}]$. 汽 车技术 2006

3. 巩梅.基 于汽车 底盘集成控制与最新技术的探析[J].时代汽车,2018(10):139-140.

4. 邓平尧. 探讨线控底盘控制技术分析及发展 [J]. 科 技风,2016(12): $16+18$.

5. 郭孔辉. 汽车操纵动力学. 长春: 吉林科学技出版社, 1991 .

6. M. 米奇克. 汽 车动力学 : $\mathrm{C}$ 卷. 第二版. 陈萌兰译. 北京 : 人民交通 出版 社, 1997 .

7. Lefier H. Consideration of lateral and longitudinal vehicle stability by function enhanced brake and stability control system. SAE 940832.1994.

8. Straub A. DSC(DynamicStabilityContro1)in BMW 7series cars. International Symposium on Advanced Vehicle Control, 1996.

9. Kraft H J. The integrated brake and stability control system of the new BMW 850i. SAE900209. 1990

10. United States National Highway Traffic Safety Administration. FMVSS No. 126 Electronic Stability Control Systems, NHTSA Final Regulatory Impact Analysis. 2007.

11. Masato Abe, Naoto Ohkubo. Yoshio Kano. A direct yaw moment control for improving limit performance of vehicle

12. 姜炜, 余卓平, 张立军。汽车底盘集成控制综述。汽车工程，2007, 29(5): $420-425$.

13. 冯虎田. 滚珠丝杜副动力学与设计基础. 北京：机械工业出版社, 2015.

14. 杨建森, 郭孔辉, 丁海涛, 等. 基于模型预测控制的汽车底盘集成控制. 吉林 大学学报：工学版, 2011(增 刊 2): 1 5.

15. Chang S. Gordon T J. Gordon. Improvement of Vehicle Dynamics using Mode1based Predictive Contro1. SAE Paper, 2009-01—0427, 2009.

16. Falcone $\mathrm{P}, \mathrm{T}$ seng $\mathrm{H}$ E, Borrelli $\mathrm{F}$, eta1. MPC based yaw and lateral stabilisation via. active front steering and braking. Vehicle System Dynamics, 2008, 46(sup1): $611-628$.

17. 徐颖. 基于信息融合技术的线控汽车状态和路面参数的仿 真估算与实验研究 [D ] . 长春: 吉林大学

18. 郑宏宇. 汽车线控转向路感模拟与主动转向控制策略研究 [D ] . 长春: 吉林大 学, 2009.

19. 余志生.汽车理论. 北京：机械工业出版社, 2002.

20. 王望予.汽车设计. 北京：机械工业出版社, 2004

21. 郑宏宇, 宗长富, 朱天军, 等. 汽车线控液压制动系统的稳定性分析 [ J ] . 农业 机械学报, 2008

22. 麦莉, 张继红, 宗长富. 基于电液制动系统的车辆稳定性控制 $[\mathrm{J}]$. 吉林大学学 报: 工学版, 2010

23. David G Ebert, Richard AKaatz. Objective CharacterizationOfVehicle Brake Feel[ J], SAE 940311 
24. 林志轩, 高晓杰. 制动踏板感觉研究现状 [ J ]. 农业装备与车辆工程, 2007 (06):4-7 .

25. 余志生. 汽车理论 $[\mathrm{M}] 5$ 版.北京: 机械工业出版社, 2009.

26. 张静涛. 综合主观评价在整车开发中的应用 [J]时代汽车, 2016(06):11-12.

27. 胡丹. 基于双扩展卡尔曼滤波的汽车状态及路面附着系数估计算法研究 $[\mathrm{D}]$. 长 春: 吉林大学 2008

28. 李弱程. 模式识别原理与应用 $[M]$. 西安: 西安电子科技大学出版社

29. 王玉海, 宋健, 李兴坤. 基于模糊推理的驾驶人意图识别研究 [ J ]

30. 宗长富, 王畅, 何否, 等. 基于双层隐式马尔科夫模型的驾驶意图辨识 $[\mathrm{J}]$. 汽 车工程 